\title{
Family engagement in Alternative Provision
}

Prof Damien Page, Leeds Beckett University

Damien.page@leedsbeckett.ac.uk

Twitter: @Damien_Page

This is an Author's Accepted Manuscript of an article to be published in British Educational Research Journal, copyright Wiley. 


\title{
Family engagement in Alternative Provision
}

\begin{abstract}
This article presents findings from research focusing on family engagement within Alternative Provision. With the existing literature on Alterative Provision scant, this article analyses the extensive assemblage of family engagement within settings as practitioners navigate complex family environments often characterised by poverty, crime and substance abuse. While settings create formalised structures of family engagement that prioritise a collaborative approach to children's development such as family learning days and daily positive phone call, equally they work to attenuate the isolation and loneliness of families who feel as excluded as their child. Yet as important as structured engagement is, practitioners within Alternative Provision also engage in the improvised pragmatism of micro-work, the work that other agencies won't or can't do such as escorting parents to medical appointments, sourcing furniture to fill empty houses or talking child out from under their bed. The article argues that family engagement in Alternative Provision is cyclical, with families informing staff of behavioural incidents or learning opportunities, information that rapidly personalises communicative and pedagogical strategies within schools. In return, teachers update parents at the end of the day, offering ideas for home learning or approaches to managing challenging behaviours. The article concludes by identifying six domains of family engagement - behavioural, emotional, safeguarding, functional, pedagogic and capacity building - that can be used within Alternative Provision settings to ensure a holistic approach that provides deep support to families to maximise the successful re-engagement of children.
\end{abstract}

\section{Introduction}

In the most recent UK data (Department for Education, 2020) in 2017-18, there were 7900 permanent exclusions, equivalent to 10 pupils in 10,000: $0.03 \%$ in primary and $0.20 \%$ in secondary. There were also 410,800 fixed period exclusions, increasing from 381,900 in 2016-17, equating to $5.08 \%$ of all children, $1.37 \%$ of all pupils in primary and $10.13 \%$ in secondary. 78,900 children had two or more fixed term exclusions with an average number of 2.2 with an average length of 2 days. The most common reason for exclusion, both permanent and fixed term, was persistent disruptive behaviour. Many of these children - especially those who are permanently or repeatedly excluded and those who require additional support with special educational needs - find themselves in Alternative Provision (AP), the most diverse sector within the education system. Here, struggling with often difficult behaviours from children, communities mostly in areas of deprivation and with resources stretched, AP settings employ creativity, ingenuity and pragmatism to try and re-engage disaffected children back into learning. Central to this mission are families and APs work tirelessly to not only involve families but to engage them, moving beyond the archetype of parent's evening and parent teacher associations towards family learning, library days and daily teacher interaction. Yet, with the majority of families with children in AP living in environments of deprivation, mainstream strategies of family engagement are insufficiently targeted and so practitioners engage in the micro-work of family support, providing a highly pragmatic and individualised assemblage of strategies in an attempt to co-create an environment where children can authentically learn. Yet while the AP sector is under-researched, family engagement is almost completely absent and this research is the aims to address that gap in the existing literature. As an exploratory study, the aim of the research was to identify the key strategies of family engagement within the AP sector and while the fieldwork focuses on the UK, the article begins with a review of the international literature that identifies a number of core issues within the sector before examining mainstream family engagement strategies 
globally and it then considers the limitations of this field in an analysis of engagement within AP. The article concludes by identifying six domains of family engagement, the first of its kind, that will allow settings to create a holistic framework to ensure that their work is both strategic and individualised to meet the needs of families and the children who are their ultimate priority.

\section{Understanding Alternative Provision: an international perspective}

Just as AP is neglected in policy terms and in the public consciousness, so too is the sector neglected in the academic literature. However, the research that does exist highlights similar issues and concerns. To begin with, there is the problem of defining the sector, described by Trotman et al (2019) as 'wide-ranging and disparate'. Harper et al (2011) argues that the complexity and diversity of AP is such that national boundedness is difficult and international comparisons problematic. Similarly, in another international review, Gutherson et al (2011) discusses the diversity of forms of provision even in-country: local authority/council run, privately owned, linked to Further Education and work-based learning settings and special schools. As such, the definition they provide is suitably all-encompassing:

schools or programmes that are set up by local authorities, schools, community and voluntary organisations, or other entities, to serve young people whose needs are not being met and who, for a variety of reasons, are not succeeding in a traditional learning environment (p.11).

For Slikwa (2008) the defining factors of AP is their emphasis on innovation in pedagogy and curriculum - a definitional lens that focuses on the child rather than the organisational type innovation that is 'gaining popularity among parents, to create more holistic approaches to education and focus on student potential for growth' (Slikwa and Yee, p175). This focus on the child is a common theme across the literature: Jalali and Morgan (2018) highlight the sense of belonging and connectedness not experienced in mainstream schools; Malcolm (2018a) discusses the emphasis on relationships between staff and children, the flexibility of structure and curriculum; McCluskey et al (2015) evidence how AP settings actively listen to parents' views on working with their children; McGregor and Mills (2012) argue that the Australian schools in their study focused on changing teaching and learning rather than changing the children, as does Quinn and Poirier (2006) in the US; Mills and McGregor (2016) detail how the curriculum was tailored to the interests and goals of students;

O'Gorman et al (2016) emphasise the prioritisation of care that creates the setting as a 'safe space'.

However, while there is consistency internationally on the child-centeredness, innovation and flexibility of APs, defining the sector by its characteristics is problematic for three reasons: it underplays the impact (or absence of) of government policy on AP and its concomitant determination of organisational forms. In the UK context, for example, Malcolm (2018a) follows the government definition provided by Taylor (2012) as 'an organisation where pupils engage in timetabled, educational activities away from school and school staff'. Here, the complexity of AP is a result of policy: just as mainstream schools are designated as local authority, independent academies or Free Schools, APs follow the same diversity including Pupil Referral Units under council control, free schools, special schools and academies within a Multi Academy Trust (MAT). Secondly, a definition that focuses on child-centredness and flexible pedagogy stretches the boundaries to include settings such as Montessori or Steiner schools (see Wiseman, 2017) which may be actively chosen by parents, with settings that are populated entirely by children who have been excluded from mainstream settings for reasons 
far beyond personal choice. For these reasons, this research will focus on those AP settings where parents have exercised little or no choice.

However, while there is a wide variety of forms of AP considered in the extant literature, there is greater similarity internationally concerning the characteristics of children who are excluded from mainstream provision and moved to AP. The first characteristic is based on ethnicity. In the US, there is the overrepresentation of Latino and African American boys (Christle et al, 2004; Noguera, 2003); in Australia (Mills and McGregor, 2016), New Zealand (Smith, 2009) and the UK (Department for Education, 2019; Malcolm, 2015) this is echoed in the overrepresentation of children of mixed white and Black Caribbean, Black Caribbean ethnicity and children from indigenous groups. The second characteristic concerns the overrepresentation of children with special educational needs and disabilities. This preponderance is documented in the UK by Trotman et al (2019) and McCluskey et al (2015) who state that $90 \%$ of pupils in Welsh AP have special educational needs. In the US, Brown (2007) and Achilles et al (2007) find a similar trend of children with special needs being much more likely to be excluded and moved to AP settings. The third characteristic is an overrepresentation of children from poorer backgrounds in Graham et al (2019) and Malcolm (2018b) in the UK, Skiba and Knesting in the US (2002) and McGregor and Mills (2012) in Australia. Finally, there are those characteristics focused on the complexity of their family environments: life trauma, family breakdowns, domestic and sexual abuse, criminality and risk of offending, health problems, teenage parenthood, a lack of family support, neglect and family conflict, poor educational histories, all feature strongly in the international literature. And accompanying these categorisations are issues of a 'problematizing' discourse surrounding children from these backgrounds, ever since the nineteenth century (Griffin, 1993). For Tucker (1999), these discourses 'aid the production and reproduction of certain ideological representations of 'appropriate' and 'inappropriate' behaviour' (p285/6) that underpin regimes within some areas of AP. Thomson and Pennacchia (2016), for example, adopt a Foucauldian approach to document the use of categorisation and surveillance to produce disciplined and docile bodies, the approach of settings based upon 'conforming subjectivities' and restricted curriculum. Adopting a similarly critical approach, Johnstone and Bradford's study of disabled 'bad boys' in alternative further education provision highlights the lack of support, low trust and disregard they encountered within the setting.

\section{Family engagement in Alternative Provision}

If the literature on AP is neglected, family engagement within the sector is even more scarce, despite several authors highlighting its importance (Michael and Frederickson, 2013; Menzies and Baars, 2015; Ruzzi and Kraemer). Most frequently, the family is positioned paradoxically as a major cause of children's removal from mainstream education as well as a major factor in their child's educational re-engagement. In Macleod et al's (2013) study of the parents of excluded children, most of the sample families were presented as complex and challenging, characterised by family breakdown, low levels of employment, mental ill health and parental absence. Here, also, parents were perceived by professionals as either a contributing factor or the cause of their children's exclusion from school - 'problems or partners' in Smith's (2009) terms. Further, parents were often seen as 'resistant and noncompliant' and 'unreasonable and demanding' (p835) in opposition to the understanding of the 'good' parent being compliant (McCarthy, 2011). In another study of the parents of excluded children by McDonald and Thomas (2003), the theme of parental anger and perception of mistreatment again occurs: parents often feel excluded from the process with genuine choice unavailable and promises unkept. In terms of authentic engagement, parents interviewed by Mills and Thomson (2018) appreciated frequent updates that emphasised 
positivity and progress being communicated frequently. Communication between the setting and parents is also optimised through the development of a trusting relationship (Mowat, 2009) as well as maintaining a triadic connection between the AP, the family and the referring school (Äärelä, Määttä and Uusiautti, 2016). Parker et al (2016) also detail the importance of family engagement - even suggesting that it was a positive factor in children's ability to cope - but that some parents felt that some staff lacked the essential skills to make this truly effective. Where communication was high quality, parents evaluated the school's actions more positively.

\section{Mainstream family engagement}

With family engagement in AP under researched, this article will next examine the international literature focusing on family engagement within mainstream settings. Over the past two decades, a significant body of international research has developed demonstrating the benefits of family engagement, most notably on children's educational achievement (Downs, 2001; Epstein, 2004; Lawson \& Alameda-Lawson, 2012), emotional development and behaviour (Cai, Moyer, \& Wang, 1997; Greenwood \& Hickman, 1991; Ferlazzo, 2011; Garbacz et al, 2016) and better child-teacher relationships (Sheldon \& Epstein, 2002; Boberiene, 2013). In addition, families who are engaged tend to have greater aspirations for their children (Hornby \& Lafaele, 2011), improved communication with their child (Wilder, 2014) and more positive relationships with teachers (Tran, 2014). However, while family involvement and engagement has clear benefits for schools, children and families themselves, there are also significant barriers, particularly when families reside in areas of deprivation. There are issues of parents' previous negative experiences of the education system (Campbell, 2011); a lack of parental understanding in school systems and interaction potential (Christenson, 2004; Sime and Sheridan, 2014); issues relating to race and class where the community is demographically different from staff in schools (Hill and Torres, 2010; Westrich and Strobel, 2013); a lack of professional development of school staff in engaging with families (Berg, et al, 2006); negative perceptions of families by teachers (Blitz et al, 2013); the othering of families in poverty (Goodall, 2019)

Consistent throughout the literature is the need for schools to move from family involvement to family engagement: the former where families take part in activities within the school, the latter where there is a culture of shared responsibility for children's educational success (Berg et al, 2006) that has the greatest positive impact (Emerson et al, 2012). While involvement carries with it a duty to create an environment that minimises barriers and craft a welcoming and supportive school environment (Davis and Lambie, 2005, Baker et al, 2016, Barr and Saltmarsh, 2014), engagement is founded upon co-responsibility (Hill and Torres, 2010) and moves the emphasis to children's learning in the home, the 'greatest lever for children's achievement' (Goodall, 2013). As such, the movement is 'away from the relationship between parents and schools, to a focus on the relationship between parents and their children's learning' (Goodall and Montgomery, 2014, p399). Underlying this perspective is a need to eliminate the discourse of fixing 'unruly' parents (Macfarlane, 2009) founded upon asymmetric power relationships (Ishimaru, 2019). This approach, a capacity building approach, draws upon the 'funds of knowledge' within families and communities that can positively change pedagogical and institutional practices. Here, Ishimaru (ibid) suggests three strategies: firstly, parent/family capacity building strategies to build knowledge and understanding of school practices and policies and embedded parent learning; secondly, culturally specific relationship building strategies, leveraging 'cultural brokers' to facilitate the recognition of the heterogeneity of families that is too often ignored; thirdly, systemic change and capacity building strategies to allow teachers to meaningfully collaborate with 
parents to build leadership and influence on the school system. From this perspective, with a greater emphasis on families as part of the community, family engagement becomes part of a 'broader moral commitment to social justice and educational equity' (Auerbach, 2009)

While the literature on family engagement within mainstream schools is useful, the applicability of these strategies of family engagement within Alterative Provision settings is limited. The majority of children remain in their mainstream schools for extended periods allowing schools to build more intimate and longitudinal relationships that can focus on capacity building at the individual and community level. In AP, children have been removed from their schools and their new setting is often temporary. As a result, staff in AP have a short window to engage families that feel excluded, isolated and failed by the education system. Here, the impact of deprivation is felt most keenly and the barriers to engagement are most acute. As such, while the literature and practice of mainstream schooling can suggest ways forward, this needs to be tempered with the unique characteristics of AP and this is what this research addresses.

\section{Methodology}

One of the problems of researching AP is the sheer diversity of the sector, encompassing everything from small, primary Pupil Referral Units to large schools within Multi Academy Trusts that cover both primary and secondary age ranges. As such, this research adopted a purposive sampling approach that aimed to include a broad cross section of institutional types but also a broad selection of staff within settings covering multiple levels of seniority and role type. In the end, five settings were selected across the north of England that provided the variety appropriate to an exploratory study included primary and secondary phases, special education, Local Authority maintained and Academies (the names are all pseudonyms):

- Ash Grove Academy was a new AP school that was part of a regional Multi Academy Trust and supported children from primary to secondary

- Oakview was a secondary AP academy that was part of a Multi Academy Trust with settings across the north of England

- Templeton Academy was a specialist school for children with social, emotional and mental health needs from primary to secondary ages

- Broadtown was a small primary setting within a large city that specialised in temporary support for children who had been excluded

- Southfield was a secondary AP setting spread over two sites within a medium sized city that had only just become 'academised' and move from under the authority of the local council

The 23 participants (all given pseudonyms) represented the complete hierarchical range from Teaching Assistants to senior leaders and from teaching to pastoral and attendance practitioners. And, just as the organisational forms were hugely varied, so were the internal structures and job roles. The bigger settings such as Ash Grove had the widest specialisation of role and included a Director of Health and Wellbeing, Family Liaison Officers, Director of Therapy and a spread of Pastoral Roles, including ones solely charged with addressing poor attendance. At the other end of the spectrum, being a small setting with just over 30 children, Broadtown housed a far more narrow set of roles although they did have a dedicated Emotional Health and Wellbeing Leader.

The intention was to gain an emic perspective, 'the insider's view of a particular group or community' (Savage, 2006: 384-385), and so adopted an interpretivist approach to capture 
the day-to-day lived experience of family engagement and so data were collected using semistructured interviews within the settings themselves and with the interviews ranging from 45 to 90 minutes. Given that the focus of the interviews could potentially include discussion of difficult topics, participants were taken through the ethics of the study, particularly the right to withdraw and were provided with details of available counselling services should they become upset. What was clear was that despite the variety within the settings, the work of family engagement was remarkably consistent and data saturation (Guest et al., 2006) occurred at a relatively early stage and so it was not considered necessary to recruit additional participants. All the interviews were recorded and transcribed in full before open coding analysis (Corbin and Strauss, 1998) to identify the initial categories and themes before selective coding occurred (Moghaddam, 2008). The article presents the key themes that emerged from the data and quotations are illustrative of these themes rather than isolated examples.

There are naturally limitations to this research. It is based upon a relatively small sample and, although data saturation occurred, the extent of generalizability is naturally limited, especially within a sector that is as diverse as AP. There is also a limitation in terms of the nature of the families are discussed. As with all research that seeks the emic perspective, the selectivity of participants, the families that they talked about, the particular children, the particular houses, is necessarily partial. For example, while some participants did discuss families from relatively wealthy backgrounds whose children had been excluded, the majority of cases discussed were families in real poverty. Care was taken to ascertain the relative balance and all participants suggested that the vast majority of families they worked with were in contexts of deprivation, but the selectivity must still be highlighted. What must also be remembered is that the literature on AP consistent highlights that children from poor backgrounds are over-represented within the sector and so this partiality is inevitable.

\section{Findings \\ Family engagement}

It was clear that family engagement was deeply embedded into the everyday routines and practices within each of the settings. However, it was equally clear that the extent and depth of engagement was determined by the size and available resources available within the settings. Mirroring the diversity of AP internationally (Harper et al, 2011) and within the UK (Gutherson et al, 2011), at one end of the spectrum was Ash Grove Academy, a new AP setting within a large Multi Academy Trust. Here, there was an extensive resource for family engagement including a Pastoral Team, a Therapy Team and Attendance Team whose sole role was to visit homes where attendance had become an issue. At the other end of the spectrum was Broadtown, a small primary ex-pupil referral unit where family engagement was part of the role of the teachers and leadership team. With a small staff-base, intensive strategies such as home visits were necessarily rare. However, what the smaller settings lacked in staffing, they made up for in resourcefulness and would engage parents whenever they could. For example, they would ensure staff were at the front gate to engage parents at drop off time, merge classes to create space for home visits or include food at events within the schools to attract families.

Engagement began at induction. With the majority of children being excluded from mainstream settings, either as a result of behaviour or, in the case of Oakview, as a result of a managed move for children that required a special school setting, the first meeting with the children and their families was crucial. What was most important was to recognise the experiences of families who were often angry and resentful as a result of the process of 
exclusion (McDonald and Thomas, 2003). This first meeting was therefore central to establishing a new climate, a new relationship, and to build trust, an essential in family engagement (Mowat, 2009).

Simon, Oakview: That is a very important meeting because it's your opportunity to get that positive relationship instantly. Because a lot of them come and they're very reluctant... a lot of them have had turbulent times in education and some parents have had difficult times in education. Most of the time they'll come quite defensive. So it's about just trying to get that relationship early on.

Pete, Southfield: Like the student, they're defensive, they're negative to schools, generally they back the child up and they blame the school and it can be a big blame culture on the previous schools if they've been let down.

Often the referring school would send scant details about the child or their home environment and so induction offered an opportunity to collect contextual details. In some instances, this was enacted through conversational strategies; in others, a life history approach was adopted with questions about birth stories, adverse childhood experiences and parental educational background. What was key was the understanding of the fragility of family engagement from the outset: whatever was promised had to be delivered or the tenuous early collaboration would be damaged.

Michelle, Southfield: They've usually been let down by the schools or by other services many, many, many times. So, if I say I'm going to do something, I do it, and I make sure that I follow it through. Once you've done that a few times, you say you're going to do something and you've done it, they do begin to trust you and... "Actually, yeah, you're not like them. Right, okay, I'll work with you."

Once children joined the schools, a detailed assemblage of engagement began. Throughout the year, each setting had a series of events that prioritised a collaborative approach, a coresponsibility (Hill and Torres, 2010) that focused on learning. Some settings had family learning days where parents would sit with their child and teachers for an extended time to discuss learning strategies and pedagogical techniques that could be emulated at home (Goodall, 2013). Others would hold interactive library sessions with an emphasis on family learning and model shared reading. However, while formalised events were a regular feature, with parents often holding negative histories of schools, more informal, social events offered a more relaxed environment for engagement: tasting a new lunch menu, Christmas fairs, family breakfasts, all attracted families and worked consistently to build an often fractured engagement history. Food attracted parents, day-time events worked better, taxis were even provided to bring parents into school. However, there were also some parents where the anxiety created by visiting schools - and sometimes even leaving the house - was so great that practitioners would go to them:

Bethany, Ash Grove: So we're seeing if we can see them outside of school, we're thinking about libraries and places like that, even just for a coffee. So, you know, a meeting with a few parents together, for a coffee, with the aim of letting them know they're not alone with some of the problems 
they're encountering. Actually, there's a lot of parents that are feeling the same as you. So, if we can build that kind of support, then the aim is obviously then to try and get them in school for that Parents Evening and meetings and updates and stuff.

What was continually highlighted was the impact of exclusion on parents as well as children. Exclusion shattered existing parental networks, precluding the social interactions at the school gate, the stigma creating a barrier and work being interrupted or even ended to care for the child. Parental loneliness was a very real factor in family engagement and practitioners were keenly aware of its impacts.

Colin, Southfield: Certain parents, what should be a two or three minute phone call is half an hour's worth because they just have to tell you about this. It is that, that bit of loneliness, a bit of a need for support.

Gordon, Templeton: All the children are taxied in and taxied out, the parents don't really meet each other, which is another way the events are quite nice that parents get to meet the parents of other children. We are starting to see some social dynamics of the kids... so informally through that, some of the kids are starting to build friendship and through that parents are in contact with each other.

As important as the planned, formal events were, the most successful strategies were the routine communications from the school. Most commonly schools would phone parents to give them an update on their child's day and achievements were always emphasised, whether academic, interpersonal or behavioural. Even when there had been issues, the positive was always emphasised (Mills and Thomson, 2018). In addition, emails and text messages were employed, whatever worked for individual parents - across the data there was no sense of one form of communication being more effective than others; instead, it was about what was most effective for individual parents:

Greg, Oakview: The phone calls are a mixture between positive and negative but as staff we make the phone call as positive as we can, so when the student gets home they're being praised at home as well just to build up positive a relationship between school and home as well.

Simon, Southfield: Could be they've struggled in most of their lessons, reluctant to go in, but actually they went in to a design technology lesson and they've started on the first project that they're on with. They've learnt how to use the fretsaw, really, actually that's a 'thank you for getting them in this morning. I really appreciate you getting them in here'. Usually, you will win them round. Get in with the early stages, the phone calls and you expect to be hit with that negative comment, 'Right, what's he done now?' 'Well no, actually, it's a positive call'.

Gordon, Templeton: We started emailing some pictures and some of the videos of what he had done. So, when he had done the cooking, he takes some home so he's actually made tea for his mum. So, it kind of builds a positive relationship at home, it's helping him to have a better relationship with his mum. 
Outside of the structured engagement, there were also opportunistic strategies such as meeting parents at the school gates.

Emma, Broadtown: Parents are happy usually dropping them off. Everyone comes in. They get breakfast. It's quite a nice social time. People can sit on their classroom tables, chat, as you would do normally at a breakfast time. So it's nice. It's nice to speak to the families on the way in. They can let you know if there's been anything that you might need to know about that will affect their day as well.

Throughout the communication, three elements were apparent: firstly, communication was an opportunity to build the relationship between school and home; secondly, the emphasis on positivity was intended to strengthen the relationship between parent and child (Wilder, 2014), which was often strained; thirdly, the emphasis on learning was a means of encouraging learning at home as well as at school (Goodall and Montgomery, 2014). In this, successful family engagement in AP was found to be cyclical with information being shared between home and school to improve behaviour, relationships and learning. If a child had had an argument at home that had created tensions, parents would call the school so that staff could be prepared to change their interactional approach or to be extra vigilant. Alternatively, if the family had a successful learning experience such as shared reading, the themes from the book would be embedded within lessons. Similarly, the communication from the school would highlight incidents in the day and suggest behaviour management techniques that the parents could try or detail learning experiences that the child particularly enjoyed that could be discussed and extended at home. Underpinning this cycle was the speed of adaptation with settings swiftly personalising the curriculum, the timetable and the communicative practices in response to the information from home. A chance conversation at the school gate would be rapidly relayed to teaching and pastoral teams who skilfully changed their practice to capitalise on learning opportunities, to extend the home experience into school. And at the end of the day, the results would be communicated back to families to further stretch the potential learning, engaging parents in the process of pedagogy and behaviour management.

Beth, Broadtown: It's nice that with some parents it is a continuation of home and school. I think that the relationship that you've got with those parents, they're the ones that you can see usually more progress with because you have got the home-school continuation rather than "what happens at home happens at home, what happens school happens at school'.

Yet while routine information tailored the learning experience, there was also the more serious information that shaped practices. Throughout the research the participants reported instances of complex lives and environments, of extreme poverty, violence, substance abuse, criminality and child sexual exploitation. Having built trust, families were surprisingly open about serious issues and, again, the settings were able to respond swiftly, alerting social services where there was a safeguarding issue, engaging the school's therapy team - where it was available - or adapting the learning environment for the child such as avoiding certain topics or adjusting staffing where an issue with a certain gender was apparent. Against this background, to address the issues outside of the school gates that had the most pronounced impact within them, APs were required to move beyond family engagement to family support. 


\section{From engagement to support}

Keith, Templeton: God there's so many incidents, you've got domestic violence in the house, you've got sexual exploitation, you've got emotional, physical neglect. Some students that we deal with, families have completely given up... it's surprising how some of them actually come in and they get straight on and work and when you start reading about their backgrounds, you think 'oh my god, how is that child even functioning, how have they even managed to get out of bed?' Some of them don't even have a bed to sleep in.

While the formalised strategies of family engagement focused on the child, all of the settings moved beyond engagement to actively supporting families themselves. As the relationship with families developed and schools learned more about their context and environment, it was clear that the standard means of engagement would be pointless if families were not adequately supported. All of the settings reported that families were often in extreme poverty - a central characteristic of children within AP internationally (Graham et al, 2019, McGregor and Mills (2012) - and so each had a budget set aside to feed and clothe the children most in need. Unlimited breakfasts were provided, storerooms held uniforms, shoes and toiletries, teachers regularly had to go out to buy coats. On home visits, children were found to be living in settings of extreme deprivation, sleeping on dirty mattresses without sheets, bare floorboards and dog faeces uncleaned. In some houses, parental mental health had deteriorated to such an extent that they couldn't leave the house, while in other instances there seemed no barrier between the home and the street, a parade of neighbours, extended families and unknown adults wandering in and out. There were children who had never been registered with the NHS and were desperate for medical attention, there were children who had never been outside of their city and there were teenage parents living in dwellings with no furniture. This sort of detailed contextual information was not provided by social services or the referring/excluding school. Instead, the settings conducted home visits.

Helena, Ash Grove: The dynamic is different. You're going into somebody's home. You've not got your team around you so, obviously, you need to be very mindful of your own personal safety, first and foremost, particularly when it's a family that you may not know very well, and it's the first time you've been when you're not quite sure who might be there. But it does put a different perspective on things, it's a different dynamic, you're in their environment.

However, it is important to highlight that, while the participants stated that the vast majority of families that they worked with were in complex contexts categorised by poverty, there were also families in contexts described as 'comfortable' and even 'well off'. Here, educational disengagement was seen as caused by a lack of boundaries or parental neglect rather than material deprivation. The need for family engagement was just as necessary as the outcomes for the children concerned - most often permanent exclusion - were the same.

In some cases, home visits were routine and an opportunity to engage families within a setting they felt more comfortable in; other visits were triggered by poor attendance or safeguarding concerns. Small APs like Broadtown and Southfield had little spare capacity and so home visits were occasional in the former and conducted by externally contracted key 
workers in the latter. Larger settings like Ash Grove and Oakview employed specific staff to conduct home visits and had the capacity to allow teachers to visits as well.

Home visits were, above all, about the unpredictable. Each setting had strict protocols for the safety of their staff such as parking the car in the right direction to facilitate a speedy exit and details of visits held by the central team but, once on the doorstep, the unpredictability necessitated an improvisational approach. At one level the improvisation was around the management of the interpersonal context. Practitioners often faced the unexpected: a horse in the garden; a mother heavy-petting with her new partner in front of them; a naked baby defecating and the parent not cleaning it for the duration of the visit; being threatened with a snake; a child that wouldn't come from under their bed; a child explaining in front of her nonchalant mother that they don't need to attend school because they want to be a drug dealer like their father; a constant stream of strangers moving in and out of the house. Improvisation was firstly a means of ensuring personal safety such as sitting by the door or mentally planning the best way to leave. But it was also about how to manage the interpersonal situation so that a proper assessment of needs and safeguarding could be accomplished. For example, navigating the house and seeing as many rooms as possible was a tricky endeavour and practitioners had to be wary not only of their safety but also of the fragile relationship they had built.

But improvisation was also about providing the support that families needed and this is where the work with families in AP most starkly differs from the engagement within mainstream schools. Here, the need was often so acute that the work of practitioners was not even about the children or their learning directly; it was about supporting parents with the basics of safety, security and wellness.

Tania, Ash Grove: It's really hard that families are left in that sort of environment and there aren't agencies out there that are willing to actually support and that's heart-wrenching. It's not nice, to the point where I've actually gone out myself and helped them to clean up houses, just because I felt that bad for them.

During home visits, practitioners cleaned, they bought curtains, they escorted parents to the doctors, they filled in forms, they advised on how to manage the process of exclusion and reintegration, they engaged in a variety of improvised micro-work that supported families directly. Although in no job description, they did the work that had to be done as they perceived it and, importantly, they were given the latitude and encouragement from senior leaders within the settings to do so.

As many of the families APs worked with were involved with a variety of social services, part of the micro-work was acting as a point of liaison, navigating through the complex and sometimes indeterminable bureaucracy of multiple agencies that families often could not. Social workers, police, the benefits office, the NHS and others provided additional complexity in lives that were already complex and AP practitioners, being liminal in the support assemblage, supported families in understanding the role and remit of each. For example, despite the contemporary discourses of some families 'working' the benefits system, families often were not accessing the funds they were entitled to such as travel for their children and so AP practitioners obtained the forms and helped families fill them out with the result that attendance would improve. In other cases, staff worked with local authorities to source furniture and white goods for families that lacked even the means to 
cook. In this micro-work, there was frustration that other agencies were not doing this work, that families would be left in such situations without adequate support. But equally, such extensive interaction with the full range of external agencies highlighted the reality of how stretched each individual agency was in a time of austerity.

\section{Discussion}

AP operates within the most complex context in the education system, working with referring/excluding schools, social services, the police, local authorities and multi-academy trusts. And within that complexity they work with families whose lives are equally complex. At the centre is the child, the ultimate priority of AP practitioners, and those whose job it is to engage with families work within the complexity to achieve their aims. As such, AP is the metaphorical expanding putty of the education sector, injecting itself into the gaps created when external agencies don't fit together. Ultimately pragmatic, they do the work that others can't, won't or refuse to do to ensure that the fundamentals of family existence are secured so that they or their colleagues can focus on the learning and development of the child. In the structured phase of family engagement, APs remain similar to mainstream schools: there is a concern to create a welcoming and supportive school environment (Baker et al, 2016); a fostering of co-responsibility (Hill and Torres, 2010) and strategies to engage families with learning in the home (Goodall, 2013); the temptation to see families as in need of 'fixing' (Macfarlane, 2009) was avoided; engagement sought to improve relationships not just between school and parents/carers but between parents/carers and their children; finally, there was a deep commitment to social justice and educational equity embedded within all the work of family engagement (Auerbach, 2009).

But it must be emphasised again that while these characteristics may be shared with mainstream settings, the nature of AP mitigates against its fullest expression and requires a different approach. Not only is there a greater concentration of families in complex and sometimes 'chaotic' contexts, the nature of AP is transitory: children are moved around the system from excluding schools, residing in APs often temporarily. In these circumstances, as useful as structured family engagement is, it can rarely be longitudinal and so practitioners within AP are required to move beyond the structural into the realm of improvisational pragmatism, not attempting to fix families but patching up contexts, rapidly and skilfully identifying the most acute difficulties and co-creating solutions within micro-work. That is not to say that this type of work was exclusive to AP - micro-work has long been a feature of settings such as youth and community work and areas of social services and the fact that these agencies have shrunk as a result of decreased government funding means that AP expands in their absence. What is unique about AP, however, is the goal of this micro-work: in AP, the work that needs to be done is solely to enable learning, to enable an effective reengagement with education. As such, this work - both the formalised, planned strategies of family engagement and the improvised micro-work of family support - is enacted through six domains: behavioural, emotional, safeguarding, functional, pedagogic and capacity building. And it is these domains that are embedded within the cycle of family engagement found within the sector.

In the behavioural domain, practitioners work with families to manage difficult behaviour, talking through critical incidents, suggesting techniques to try and home and modelling behaviour management during home visits. But it also includes managing the behaviours of the families themselves, challenging inappropriate communication or outbursts from parents and carers, setting boundaries and expectations while at the same time modelling professional, collaborative interaction, keeping their word and following through on all 
actions to the letter. The emotional domain, firstly focuses on the needs of the child. Within the cycle, the affective nature of settings is emphasised, parents and AP practitioners share notes on the mood and wellbeing of the children, they look for signs, they talk about affective incidents and how to manage them, how to therapise interactions. But within this domain, practitioners also manage the emotions of families, they comfort and coach, they provide a listening ear, they empathise, they develop an extensive understanding of the affective context of the parents and the impact of their environments and they provide opportunities to socialise with other families who find themselves similarly excluded. The next domain, safeguarding, while a staple within education, takes on a new significance within AP and, as opposed to the reactivity of mainstream safeguarding, in AP this domain is highly proactive. Safeguarding is detective work: signs are spotted, behavioural clues gleaned, instincts are followed and, where there is concern, home visits position practitioners within frontline assessment of concern. But while the most serious of cases are reported to the relevant social service, they also move to the next domain, that of the functional. With a driving sense of empathy and compassion, the micro-work within homes is highly functional with practitioners fixing the environment (notably not the family which was not expressed within this research): they clean, they guide on nutrition and hygiene, they source furniture, white goods and curtains, they escort both children and parents/carers to doctors and they help to fill in forms. But this functionalism is not purely driven by compassion, it is also driven by the knowledge that if they don't do it, no one will, with every external agency seemingly stretched to capacity, under-resourced and unable to engage in this micro-work. The next domain, the pedagogic, is again firmly embedded within the cycle with practitioners - usually but not exclusively teachers or classroom assistants - sharing not only classroom activities but how children approached work, what particularly motivated them and how and what they learned. At the same time, suggestions were made to families about how learning could be extended within homes and what elements of pedagogy might work for parents and how learning could be scaffolded. The final domain was capacity building, echoing Ishimaru's (2019) framework, but within a context of temporariness and transition which limited the extent and prioritisation. Capacity building within AP focused primarily on two main practices: firstly helping families to navigate the complexity of the education system, understanding the legality of exclusions and how to assert themselves within a process that often excluded them as well as their child. Here, parents and carers were advised of their rights and even accompanied to meetings with the excluding schools where practitioners acted as advocates for parents and challenged inappropriate and unethical practices. Secondly, they worked with families to understand the additional complexities of social services, how to work with social workers or police and how to navigate the benefits system.

By framing the work of family engagement within a set of domains, there is an echo of Maslow, the spectre of a hierarchy. But the domains of family engagement within AP do not function as a hierarchy - hierarchies seek to homogenise, a tendency that was not found within the data. Participants in this research treated each family as unique, they talked in detail about the idiosyncrasies of the families they worked with and the highly individualised nature of their micro-work. Each of the domains was addressed during family engagement, but the extent and depth of each was different. While the majority of families lived within contexts of deprivation, there were also some families who lived in large, well-appointed homes where the issue was not poverty but a lack of boundaries and parental structures. Equally, some families lived in tiny, bare homes that were spotlessly clean and the children expertly cared for. In this sense, while the domains are not a hierarchy, they are equally not a pick-and-mix: where family engagement was most authentic, where it achieved the most, each of the domains were attended to, even when time was short and exclusion temporary. 
But there are dilemmas for family engagement practitioners in AP, risks than underpin the domains. Firstly, there is the risk that families require so much attention that more focused work with the children could, potentially, become secondary. When practitioners were tasked with increasing family learning and creating a collaborative approach to education - the pedagogic domain - the needs of families would sometimes pull them more into the pragmatic domain; other times the behaviour of families towards AP staff would equally pull from the educationally-focused domains. As such, the balance between family and child remained a potentially challenging dialectic. Secondly, the complexity of home environments, no matter how extreme they appeared to staff, were normal for the children. Poverty, crime, domestic and sexual abuse and addiction were all routine, they were part of the children's daily lives in their community. With a commitment to improving the life chances of children, practitioners had to work to change children's perspectives, they had to help children understand that there was another way, that what they saw as normal was counterproductive to their chances of success. When a child reports that they want to be a drug dealer like their father, practitioners work to present an alternative vision of life, a life without criminality, a life that breaks with the generational issues practitioners reported. And while they challenged this normalisation on a daily basis, they had to be careful not to damage the relationship between child and parents, not to attach blame or to present families as the problem. Here, more than anywhere, was the fragility of family engagement: to challenge the normalisation of crime, violence and abuse without damaging the engagement with families that was so crucial to the educational re-engagement of the child. Unfortunately, the success of this balancing act was usually impossible to judge. Instead, success was found in the indicative, the small wins, the day without outburst, a lesson of deep learning, a book read, an application to a college course. But perhaps the best sign was when each of these indices was co-created with families, whenever a step, no matter how small, was jointly taken between the parent/carer and the child towards learning. And here, within the participants' deep commitment to a partnership approach, was the avoidance of the 'deficit narrative', the sense that the practitioners were somehow the 'saviours' of 'troubled families' (see for example Hayden and Jenkins, 2014). While the vast majority of families discussed by the participants were within contexts of deprivation, there was no sense from the participants themselves that the families themselves required fixing, there was no sense of saviourhood. Instead, there was a focus on the contexts of deprivation, the barriers that prevented successful re-engagement with education, both for the children and their families. Families were not the problem, poverty was. However, it must be acknowledged that families were not part of this research and so while saviourhood was not present within the data collected from this research, it is always possible that families themselves hold a different view.

\section{Conclusion}

Working within the most complex educational context with families within the most complex environments, APs operate within the gaps left by other agencies for the good of the children within their care. Yet while the needs of children remained their ultimate priority, the needs of family often proved to be the major barrier to educational success and so settings had developed a sophisticated assemblage of engagement and support that was simultaneously highly structured and planned on one hand and improvised and spontaneous micro-work on the other. This assemblage operated within six domains - behavioural, emotional, safeguarding, functional, pedagogic and capacity building - that were attenuated to the characteristics and needs of each individual family. Yet in addition to providing a means of analysis, in a practice sense, the domains offer a means through which settings can structure 
their family engagement, to apply a framework that will provide the very best, holistic support to families and children while preserving the improvisational micro-work so essential to best practice. At an organisational level, structured engagement can be mapped against the domains ensuring that individuals and teams can offer targeted support in the most effective and timely manner so that no matter how short or long children remain within AP, a rigorous framework can be provided to meet the needs of all families. The domains can also provide the basis for individual practice, for self-evaluating micro-work and structuring the highly detailed knowledge of family need and the differentiated actions taken. In this way, as an organisational and personal analytical tool, the domain framework may enable settings to systematise their practice and ensure that, while families and children may be transitory, the organisational expertise-memory of family engagement is retained and employed with all families who find themselves in settings they had often never been aware of.

\section{References}

Achilles, G. M., McLaughlin, M. J., Croninger, R. G. (2007). Sociocultural correlates of disciplinary exclusion among students with emotional, behavioral, and learning disabilities in the SEELS national dataset. Journal of Emotional and Behavioral Disorders, 15(1), 33-45.

Auerbach, S. (2009). Walking the walk: Portraits in leadership for family engagement in urban schools. The School Community Journal, 19(1), 9-32.

Baker, T.L., Wise, J., Kelley, G. and Skiba, R.J. (2016). Identifying barriers: Creating solutions to improve family engagement. School Community Journal, 26(2), 161-184.

Barr, J. and Saltmarsh, S. (2014). "It all comes down to the leadership" The role of the school principal in fostering parent-school engagement. Educational Management Administration \& Leadership, 42(4), 491-505.

Berg, A.C., Melaville, A. and Blank, M.J. (2006). Community \& Family Engagement. Principals Share What Works. Coalition for Community Schools

Blitz, L.V., Kida, L., Gresham, M. and Bronstein, L.R. (2013). Prevention through collaboration: Family engagement with rural schools and families living in poverty. Families in Society, 94(3), 157-165.

Boberiene, L.V. (2013). Can policy facilitate human capital development? The critical role of student and family engagement in schools. American journal of Orthopsychiatry, 83(2-3), 346.

Brown, T.M. (2007). Lost and turned out: Academic, social, and emotional experiences of students excluded from school. Urban Education, 42(5), 432-455.

Cai, J., Moyer, J. C., \& Wang, N. (1997). Parental roles in students' learning of mathematics: An exploratory study. Paper presented at the annual meeting of the American Educational Research Association, Chicago, IL

Campbell, C. (2011). How to involve hard-to-reach parents: encouraging meaningful parental involvement with schools. National College for School Leadership, available online: https://dera.ioe.ac.uk/12136/1/download\%3Fid=156367\&filename=how-to-involvehard-to-reach-parents-full-report.pdf

Christle, C., Nelson, M., \& Jolivette, K. (2004). School characteristics related to the use of suspension. Education and the Treatment of Children, 27(4), 509-526.

Corbin J and Strauss A (1998). Basics of Qualitative Research: Techniques and Procedures for Developing Grounded Theory. Sage: London.

Davis, K.M. and Lambie, G.W. (2005). Family engagement: A collaborative, systemic 
approach for middle school counselors. Professional School Counseling, 9(2), 144151

Department for Education (2020). Permanenet and Fixed Exclusions in England 2017 to 2018. Available online:

https://assets.publishing.service.gov.uk/government/uploads/system/uploads/attachme nt_data/file/820773/Permanent_and_fixed_period_exclusions_2017_to_2018_main_text.pdf

Downs,A.(2001).It's all in the family: Middle schools share the secrets of parent Engagement. Middle Ground, 4(3), 10-15.

Emerson, L., Fear, J., Fox, S. and Sanders, E. (2012). Parental engagement in learning and schooling: Lessons from research. A report by the Australian Research Alliance for Children and Youth (ARACY) for the Family-School and Community Partnerships Bureau: Canberra.

Epstein,J.L.(2004). Meeting NCLB requirements for family involvement. Middle Ground, 8(1), 14-17.

Ferlazzo, L. (2011). Involvement or Engagement? Educational Leadership, 68(8), 10-14.

Garbacz, S.A., McIntosh, K., Eagle, J.W., Dowd-Eagle, S.E., Hirano, K.A. and Ruppert, T. (2016). Family engagement within schoolwide positive behavioral interventions and supports. Preventing School Failure: Alternative Education for Children and Youth, 60(1), pp.60-69.

Goodall, J., 2013. Parental engagement to support children's learning: a six point model. School Leadership \& Management, 33(2), 133-150.

Goodall, J. (2019). Parental engagement and deficit discourses: absolving the system and solving parents. Educational Review, 1-13.

Goodall, J. and Montgomery, C. (2014). Parental involvement to parental engagement: A continuum. Educational Review, 66(4), 399-410.

Graham, B., White, C., Edwards, A., Potter, S. and Street, C. (2019). School exclusion: a literature review on the continued disproportionate exclusion of certain children. Department for Education

Greenwood, G. E., \& Hickman, C. W. (1991). Research and practice in parent involvement: Implications for teacher education. The Elementary School Journal, 9(3), 279-288

Griffin, C. (1993) Representations of Youth (Cambridge, Polity Press).

Guest G, Bunce A and Johnson L (2006) How many interviews are enough? An experiment with data saturation and variability. Field Methods, 18(1): 59-82.

Gutherson, P., Davies, H. and Daszkiewicz, T. (2011). Achieving successful outcomes through alternative education provision: An international literature review. $C f B T$ Education Trust.

Hayden, C. and Jenkins, C., 2014. 'Troubled Families' Programme in England: 'wicked problems' and policy-based evidence. Policy Studies, 35(6), pp.631-649.

Hill, N.E. and Torres, K. (2010). Negotiating the American dream: The paradox of aspirations and achievement among Latino students and engagement between their families and schools. Journal of Social Issues, 66(1), 95-112.

Hornby, G., \& Lafaele, R. (2011). Barriers to parental involvement in education: An explanatory model. Educational Review, 63(1), 37-52

Ishimaru, A.M., 2019. From family engagement to equitable collaboration. Educational Policy, 33(2), 350-385.

Jalali, R. and Morgan, G. (2018). 'They won't let me back. 'Comparing student perceptions across primary and secondary Pupil Referral Units (PRUs). Emotional and Behavioural Difficulties, 23(1), 55-68.

Johnston, C. and Bradford, S., 2019. Alternative spaces of failure. Disabled 'bad boys' in 
alternative further education provision. Disability \& Society, 34(9-10), pp.1548-1572. Lawson, M. A., \& Alameda-Lawson, T. (2012). A case study of school-linked, collective parent engagement. American Educational Research Journal, 49(4), 651-684

Macfarlane, K. (2009). Navigating a treacherous game: conceptualising parental engagement in contemporary Queensland schooling. British Journal of Sociology of Education, 30(5), 563-576.

Macleod, G., Pirrie, A., McCluskey, G. and Cullen, M. (2013). Parents of excluded pupils: customers, partners, problems?. Educational Review, 65(4), 387-401.

Malcolm, A. (2015) 'Alternative provision as an educational option: understanding the experiences of excluded young people'. Professional Doctorate Thesis. University of Bedfordshire.

Malcolm, A., (2018). Heads of alternative provision: committed to realising young peoples' potential in an unregulated market. International Journal of Inclusive Education, 114.

McCarthy, D.J. (2011). Classing early intervention: Social class, occupational moralities and criminalization. Critical Social Policy 31(4), 1-22.

McCluskey, G., Riddell, S. and Weedon, E. (2015). Children's rights, school exclusion and alternative educational provision. International Journal of Inclusive Education, 19(6), 595-607.

McGregor, G. and Mills, M. (2012). Alternative education sites and marginalised young people: 'I wish there were more schools like this one'. International Journal of Inclusive Education, 16(8), 843-862.

Menzies, L and Baars, S. (2015). The alternative should not be inferior: what now for pushed out learners? Inclusion Trust. Available online: https://www.lkmco.org/wpcontent/uploads/2015/02/Inclusion-Trust_What-Now-For-Pushed-Out-Learnersfinal.pdf

Michael, S. and Frederickson, N. (2013). Improving pupil referral unit outcomes: pupil perspectives. Emotional and Behavioural Difficulties, 18(4), 407-422.

Mills, M. and McGregor, G. (2016). Alternative education: Providing support to the disenfranchised. International Journal of Child, Youth and Family Studies, 7(2), 198-217.

Moghaddam A (2006). Coding issues in grounded theory. Issues in educational research, $16(1), 52-66$.

Mowat, J. (2009). The inclusion of pupils perceived as having social and emotional behavioural difficulties in mainstream schools: a focus upon learning. Support for Learning, 24(4), 159-169

Noguera, P. (2003). The trouble with Black boys: The role and influence of environmental and cultural factors on the academic performance of African American males. Urban Education, 38(4), 431-459.

O'Gorman, E., Salmon, N. and Murphy, C.A. (2016). Schools as sanctuaries: A systematic review of contextual factors which contribute to student retention in alternative education. International journal of inclusive education, 20(5), 536-551.

Parker, C., Paget, A., Ford, T. and Gwernan-Jones, R. (2016). 'He was excluded for the kind of behaviour that we thought he needed support with...'A qualitative analysis of the experiences and perspectives of parents whose children have been excluded from school. Emotional and Behavioural Difficulties, 21(1), 133-151.

Quinn, M. M., \& Poirier, J. M. (2006). Study of effective alternative education programs: Final grant report. American Institutes for Research.

Ruzzi, B.B. and Kraemer, J., 2006. Academic Programs in Alternative Education: An Overview. National Center on Education and the Economy (NJ1). 
Savage, J. (2006). Ethnographic evidence. Journal of Research in Nursing 11(5), 383-93.

Sheldon, S. B., and Epstein, J. L. (2002). Improving student behavior and school discipline with family and community involvement. Education and Urban Society, 35(1), 4-26

Sime, D. and Sheridan, M. (2014). 'You want the best for your kids': improving educational outcomes for children living in poverty through parental engagement. Educational Research, 56(3), 327-342.

Skiba, R. J., and Knesting, K. (2002). Zero tolerance, zero evidence: An analysis of school disciplinary practice. In R. J. Skiba \& G. G. Noam (Eds) Zero tolerance: Can suspension and expulsion keep schools safe? (17-43: Jossey-Bass

Sliwka, A. (2008). The Contribution of Alternative Education. In OECD Innovating to Learn, Learning to Innovate, Paris: OECD.

Sliwka, A., and Yee, B. (2015). From Alternative Education to the Mainstream: Approaches in Canada and Germany to preparing learners to live in a changing world: from alternative education to the mainstream. European Journal of Education, 50 (2), 175 183.

Smith, A.P. (2009). New Zealand families' experience of having a teenager excluded from school. Pastoral Care in Education, 27(2), 89-100.

Taylor, C., 2012. Improving alternative provision. https://www.oswaldtwistle.org/files/files/Taylor_Report_on_AP.pdf

Thomson, P. and Pennacchia, J. (2016). Hugs and behaviour points: Alternative education and the regulation of 'excluded' youth. International Journal of Inclusive Education, 20(6), pp.622-640

Tran, Y. (2014). Addressing reciprocity between families and schools: Why these bridges are instrumental for students' academic success. Improving Schools, 17(1), 18-2

Trotman, D., Enow, L. and Tucker, S. (2019). Young people and alternative provision: Perspectives from participatory-collaborative evaluations in three UK local authorities. British Educational Research Journal, 45(2), 219-237.

Tucker, S.A., 1999. Making the link: dual 'problematization', discourse and work with young people. Journal of Youth Studies, 2(3), 283-295

Westrich, L. and Strobel, K. (2013). A study of family engagement in Redwood City community schools. John W. Gardner Center for Youth and Their Communities. Available online: https://gardnercenter.stanford.edu/sites/g/files/sbiybj11216/f/Family\%20Engagement \%20in\%20Redwood\%20City\%20Schools\%20Issue\%20Brief.pdf

Wilder, S. (2014). Effects of parental involvement on academic achievement: A metasynthesis. Educational Review, 66(3), 377-397

Wiseman, P., 2017. Alternative education provision-international perspectives. In International and Comparative Education (7-20). Routledge. 